\title{
Prevalencia y genotipos del virus del papiloma humano en muestras de tejido laríngeo de pacientes con cáncer de laringe del noreste de México
}

\section{Prevalence and genotypes of the human papillomavirus in laryngeal tissue samples of patients with laryngeal cancer from Northeastern Mexico}

\author{
Gerardo C. Palacios-Saucedo ${ }^{*}$, José M. Vázquez-Guillén², Lydia G. Rivera-Morales², \\ Ricardo García-Cabello', Ethel C. Sánchez-Fresno ${ }^{1}$, Martha S. Montalvo-Bañuelos ${ }^{3}$, \\ Julio C. Serna-Hernández', Silvia J. Hernández-Martínez', Edmundo E. Castelán-Maldonado', \\ Ángel Zavala-Pompa², Gustavo I. Amador-Patiño y Cristina Rodríguez-Padilla ${ }^{2}$ \\ 'División de Investigación en Salud, Departamento de Otorrinolaringología y Departamento de Anatomía Patológica, Unidad Médica de Alta \\ Especialidad Hospital de Especialidades No. 25, Instituto Mexicano del Seguro Social (IMSS), Monterrey; '2Laboratorio de Inmunología y Virología, \\ Facultad de Ciencias Biológicas, Universidad Autónoma de Nuevo León, San Nicolás de los Garza; ${ }^{3}$ Departamento de Foniatría, Hospital General \\ de Zona No. 6, IMSS, San Nicolás de los Garza, Nuevo León, México
}

\section{Resumen}

Antecedentes: El cáncer de laringe representa el 21.7\% de las neoplasias malignas de vías aerodigestivas superiores. La prevalencia del virus del papiloma humano (VPH) en el cáncer de laringe oscila entre el 0 y el $80 \%$. Método: Se incluyeron 112 muestras de tejido laríngeo de pacientes con cáncer de laringe. Se amplificó el ADN y se analizó la presencia y el genotipo del VPH mediante hibridación reversa (INNO-LiPA $\left.{ }^{\Theta}\right)$. Se realizaron pruebas de ji cuadrada, Fisher y $t$ de Student no pareada. Resultados: Se incluyeron muestras de 107 hombres (95.5\%) y 5 mujeres (4.5\%), con una edad de $65.3 \pm 10.1$ años, con antecedente de tabaquismo 108 (96.4\%), alcoholismo 9 (8.0\%) y carcinoma epidermoide moderadamente diferenciado queratinizante 96 (85.7\%). Se identificó $\mathrm{VPH}$ en 60 (53.5\%), VPH-11 en 51 (45.5\%), VPH-52 en 27 (24.1\%), VPH-16 en 9 (8.0\%), VPH-45 en 3 (2.6\%) y coinfección por más de un genotipo en 31 (27.6\%). No hubo diferencia entre pacientes con y sin infección por VPH en cuanto a edad, sexo, localización, diagnóstico histopatológico, tabaquismo ni alcoholismo ( $p>0.05)$. Conclusiones: La prevalencia de infección por VPH en el cáncer de laringe fue del 53.5\%, con coinfección por más de un genotipo en el 27.6\%. El genotipo más frecuente fue el VPH-11, tipo de bajo riesgo, seguido por el VPH-52, de alto riesgo oncogénico.

PALABRAS CLAVE: Cáncer de laringe. Virus del papiloma humano. VPH. Genotipo.

\begin{abstract}
Background: Laryngeal cancer represents $21.7 \%$ of malignancies of the upper aerodigestive tract. The prevalence of the Human Papillomavirus (HPV) in laryngeal cancer ranges 0 to $80 \%$. Methods: We included 112 laryngeal tissue samples obtained from patients with laryngeal cancer. DNA was extracted and amplified by PCR. HPV presence and genotype were analyzed by the reverse hybridization INNO-LiPA ${ }^{\circledast}$ assay. Chi-square, Fisher's and unpaired Student $\mathrm{t}$ tests were used. Results: Samples from 107 male (95.5\%) and 5 female patients (4.5\%) were evaluated, aged 65.3 \pm 10.1 years, 108 with
\end{abstract}

\author{
Correspondencia: \\ *Gerardo C. Palacios-Saucedo \\ Fidel Velásquez y Lincoln, s/n \\ Col. Nueva Morelos \\ C.P. 64320 , Monterrey, N.L., México \\ E-mail: palsaugc@gmail.com; \\ gerardo.palacios@imss.gob.mx
}

Fecha de recepción: 23-03-2018

Fecha de aceptación: 14-05-2018

DOI: 10.24875/CIRU.18000297
Cir Cir. 2018;86:499-507

Contents available at PubMed www.cirugiaycirujanos.com 
smoking history (96.4\%), 9 with alcoholism history (8.0\%), and in 96 the histological diagnosis was moderately differentiated keratinizing squamous cell carcinoma (85.7\%). HPV was detected in 60 samples (53.5\%), HPV-11 in 51 (45.5\%), HPV-52 in 27 (24.1\%), HPV-16 in 9 (8.0\%), HPV-45 in $3(2.6 \%)$, and coinfection by more than one genotype in 31 (27.6\%). There was no difference between patients with and without HPV infection with respect to age, sex, tumor location and histology, smoking and alcoholism history ( $p>0.05)$. Conclusions: The prevalence of HPV infection in laryngeal cancer was $53.5 \%$ with coinfection with more than one genotype in $27.6 \%$. The most frequent genotype was HPV-11, an oncogenic low-risk genotype, followed by HPV-52, a high-risk genotype.

KEY WORDS: Laryngeal cancer. Human papillomavirus virus. HPV. Genotype.

\section{Introducción}

El cáncer de laringe representa el $21.7 \%$ de las neoplasias malignas de las vías aerodigestivas superiores, pero tan solo el $0.8 \%$ de la totalidad de las neoplasias malignas'. El cáncer de laringe tiene como principales factores de riesgo el tabaquismo y el alcoholismo. La información en la literatura internacional es escasa con respecto a otros posibles factores de riesgo, tales como el reflujo gastroesofágico y la infección por el virus del papiloma humano (VPH) ${ }^{2-4}$.

EI VPH es un virus ADN de doble cadena cuya actividad tumoral se asocia principalmente a las oncoproteínas E6 y E7.Los genotipos del VPH se dividen en aquellos de bajo riesgo oncogénico $(6,11,40,42$, $53,54$ y 57$)$ y aquellos de alto riesgo $(16,18,32,35$, $39,45,51,56$ y 58$)^{5}$. El VPH se ha identificado como causante de diferentes cánceres escamosos de cabeza y cuello, siendo el VPH-16 el más frecuentemente asociado al carcinoma de laringe ${ }^{6-9}$.

En la literatura internacional se ha reportado la presencia del VPH en el cáncer de laringe en un porcentaje que oscila entre el 0 y el $80 \% \%^{9-17}$. En México existen publicados tres estudios referentes a la prevalencia del VPH en el cáncer de laringe. En el primero de ellos, 16 de 32 muestras de pacientes fueron positivas para VPH; el segundo halló que solo 4 de 16 muestras estudiadas presentaban infección por VPH; y en el tercer estudio únicamente 2 de 45 muestras fueron positivas para el VPH ${ }^{9,18,19}$. En el presente estudio se evaluaron la prevalencia y los genotipos del VPH en muestras de tejido laríngeo de pacientes con cáncer de laringe de una unidad médica de tercer nivel de atención del noreste de México.

\section{Método}

Se recopilaron muestras incluidas en bloques de parafina de tejido laríngeo con diagnóstico de cáncer, que fueron obtenidas por biopsia o resección completa en el departamento de otorrinolaringología y anatomía patológica de una unidad médica de tercer nivel de atención de la ciudad de Monterrey, localizada en el noreste de México. Se incluyeron las muestras tomadas y procesadas en el periodo de 2012 a 2015, las cuales resultaron ser 112 . Se eliminaron aquellas con necrosis extensa, definida histológicamente como la presencia de tejido necrótico no apropiado para la recuperación de ADN en más del $50 \%$ de la laminilla, las muestras con material no útil por procesamiento histológico inadecuado debido a una mala fijación de la muestra, por muestra insuficiente cuando por escasa muestra de tejido no se contó con células representativas de neoplasia, y las procedentes de pacientes cuyo expediente no se encontró disponible en el archivo del hospital. Se recopiló de los expedientes clínicos la información sobre las características clínicas de los pacientes, tales como edad, sexo, antecedente de tabaquismo, etilismo, localización del tumor y diagnóstico histopatológico.

\section{Extracción del ADN}

Se tomaron dos fragmentos del tejido embebido en parafina por punch (sacabocados). Para la obtención de ADN se empleó el kit Nucleo Spin ${ }^{\circledR}$ FFPE DNA (Macherey-Nagel, Düren, Alemania). Los fragmentos se colocaron en un tubo de microcentrífuga de $1.5 \mathrm{ml}$ y se añadieron $400 \mu \mathrm{l}$ de reactivo para disolver la parafina; se incubó por 3 minutos a $60^{\circ} \mathrm{C}$, se agitó la muestra en vórtex y se dejó atemperar a temperatura ambiente. Se agregaron $100 \mu$ de buffer FL y se centrifugó a 11,000 $\times$ g por 1 minuto, con formación de dos fases: inferior-acuosa (tejido y buffer) y superior-orgánica (parafina). Se añadieron $10 \mu \mathrm{l}$ de proteinasa $\mathrm{K}$ en la fase inferior y se mezcló con pipeta; luego se incubó a temperatura ambiente por 3 horas. Se añadieron $100 \mu$ de Decrosslink ${ }^{\circledR}$ buffer y se incubó a $90{ }^{\circ} \mathrm{C}$ por 30 minutos para eliminar el material intercalado en el ADN aislado. Terminado el proceso 
se dejó reposar a temperatura ambiente por 2 minutos. Se adicionaron $200 \mu \mathrm{l}$ de etanol (96-100\%) y se mezcló en vórtex (2-5 segundos), se centrifugó por 30 segundos a 11,000 $\times$ g para separar las fases. La fase acuosa fue pipeteada y colocada en la columna NSFFPE instalada en un tubo colector de $2 \mathrm{ml}$. El ADN presente en la muestra se une a la membrana de sílice de la columna. Se eliminaron las sales, los metabolitos y los componentes celulares macromoleculares con dos ensayos de lavado y centrifugación (400 $\mu \mathrm{l}$ buffer B5, 2,000 $\times \mathrm{g} 30$ segundos y $11,000 \times \mathrm{g} 30$ segundos). El tubo colector utilizado fue eliminado y se colocó la columna en un nuevo tubo de microcentrífuga. Se colocaron $20 \mu \mathrm{l}$ de buffer BE en el centro de la membrana de sílice y se centrifugó por 30 segundos a $11,000 \times \mathrm{g}$, con lo que se obtuvo un eluido final de ADN (15-20 $\mu$ l) cuya pureza y concentración fueron analizadas por espectrofotometría.

\section{Amplificación del ADN viral}

El genoma viral fue analizado utilizando el kit de hibridación linear reversa INNO-LiPA ${ }^{\circledR}$ HPV Genotyping Extra (Innogenetics, Bélgica). Se preparó un Master Mix en hielo, conteniendo $37.7 \mu$ de AMP MIX (primers biotinilados, desoxirribonucleótidos, $\mathrm{MgCl}_{2} \mathrm{y}$ $\mathrm{NaN}_{3}$ al 0.05\% como conservador). Se agregaron 2.3 $\mu \mathrm{l}$ de ENZ MIX (AmpliTaq Gold ${ }^{\circledR}$ ) y a esta mezcla se añadieron $10 \mu$ del eluido final de ADN. Como control positivo de ADN se utilizaron $10 \mu \mathrm{l}$ del control provisto por el kit, el cual fue positivo como control interno de hibridación en todos los experimentos y corresponde al VPH-6. Como control negativo se utilizaron en todos los experimentos $10 \mu \mathrm{l}$ de $\mathrm{H}_{2} \mathrm{O}$ destilada libre de ADN.

\section{Detección y tipificación}

- Hibridación: se utilizaron $10 \mu \mathrm{l}$ del producto amplificado biotinilado para la hibridación en la tira, los cuales se mezclaron con $10 \mu \mathrm{l}$ de solución de desnaturalización en los canales de hibridación independientes sostenidos en una placa plástica por 5 minutos a temperatura ambiente. Se mezclaron $10 \mu \mathrm{l}$ del producto amplificado biotinilado con $10 \mu \mathrm{l}$ de solución de desnaturalización durante 5 minutos a temperatura ambiente en cada canal de hibridación independiente de la placa plástica provista por el fabricante. Después se agregaron $2 \mathrm{ml}$ de solución de hibridación a cada canal y se mezclaron por pipeteo. Se colocó una tirilla reactiva previamente marcada a su respectivo canal. Para finalizar esta etapa, se colocaron los canales en un baño de agua a $49{ }^{\circ} \mathrm{C}$ con agitación (aproximadamente a 80 agitaciones por minuto) por 60 minutos.

- Lavado: después de la hibridación, la placa plástica se sostuvo en un ángulo que permitía aspirar con una pipeta el líquido contenido en cada canal. Luego se agregaron $2 \mathrm{ml}$ de la solución de lavado precalentado a $37^{\circ} \mathrm{C}$ a cada canal y se agitaron por 10 a 20 segundos a temperatura ambiente. Este paso fue repetido tres veces, dejando incubar en el último en un baño de agua a $49{ }^{\circ} \mathrm{C}$ en agitación por 30 minutos.

- Desarrollo de coloración: todas las incubaciones posteriores se llevaron a cabo a una temperatura de 20 a $25^{\circ} \mathrm{C}$ en agitación. Cada tirilla fue lavada dos veces por 1 minuto usando $2 \mathrm{ml}$ de la solución de enjuague. Luego se añadieron $2 \mathrm{ml}$ del conjugado a cada canal y se incubaron por 30 minutos con agitación. Tras aspirar el líquido de cada canal, cada tirilla se lavó dos veces usando la solución de enjuague en agitación por 1 minuto, y posteriormente se realizó el mismo paso utilizando $2 \mathrm{ml}$ de buffer de sustrato. Después de esto se aspiró el buffer para luego agregar $2 \mathrm{ml}$ de solución de sustrato a cada canal, dejándolos en incubación por 30 minutos en agitación. Este último paso brindaba coloración de las líneas que presentaban hibridación. La reacción se detuvo añadiendo $2 \mathrm{ml}$ de agua destilada en agitación por 3 minutos.

- Interpretación de resultados: las tiras de hibridación cuentan con tres controles, que consisten en una banda control del conjugado, una banda control de ADN humano y dos bandas control de VPH. Posteriormente se procedió a la lectura del número de bandas reactivas resultantes del proceso de hibridación entre los productos de amplificación y las sondas inmovilizadas en la tira. El patrón de bandas de cada tira fue comparado con la tabla de interpretación brindada por el fabricante para determinar el/los genotipo/s presentes en cada muestra.

\section{Análisis estadístico}

Para el análisis de los resultados se utilizaron frecuencias absolutas, porcentajes, medias y desviaciones estándar. Se utilizaron además la prueba de ji al cuadrado, la prueba de la probabilidad exacta de 
Fisher y la prueba $t$ de Student para muestras independientes. El análisis se realizó con el paquete SPSS v. 20.0 para Windows, y se consideró como significativo un valor de $p<0.05$.

\section{Aspectos éticos}

El presente estudio se ajusta a los principios éticos de la Declaración de Helsinki y sus desarrollos ulteriores, y a los Principios de las Buenas Prácticas Clínicas. Así mismo, está en concordancia con las normas establecidas en la Ley General de Salud y con la normatividad institucional en materia de investigación en salud. El protocolo fue autorizado con No. de registro R-2014-785-055 por la Comisión Nacional de Investigación Científica de la institución donde fue realizado el estudio. No se requirió obtención de consentimiento informado ya que únicamente se revisaron los expedientes clínicos de los pacientes.

\section{Resultados}

Se incluyeron 112 muestras de tejido laríngeo correspondientes a 112 pacientes con cáncer de laringe de una unidad médica de tercer nivel de atención del noreste de México. Estas muestras correspondieron a 72 laminillas y bloques de parafina obtenidos por biopsia (64.3\%) y a 40 laminillas y bloques de parafina obtenidos por laringectomía (35.7\%). Cinco pacientes fueron del sexo femenino (4.5\%) y 107 del masculino (95.5\%). La media de edad fue de $65.3 \pm 10.1$ años. La mayoría de los pacientes $(n=108)$ tenían el antecedente de tabaquismo $(96.4 \%)$, y pocos $(n=9)$ tenían el antecedente de alcoholismo positivo (8.0\%). La localización más frecuente de los tumores fue la glótica, en 65 pacientes (58\%), seguida de la transglótica en $26(23.2 \%)$ y la supraglótica en 17 (15.2\%). El diagnóstico histológico más frecuente fue el de carcinoma epidermoide moderadamente diferenciado queratinizante, en 96 pacientes (85.7\%), seguido por el carcinoma epidermoide bien diferenciado invasor en $11(9.8 \%)$, el carcinoma epidermoide moderadamente diferenciado no queratinizante en $3(2.7 \%)$ y el carcinoma epidermoide poco diferenciado en 2 (1.8\%) (Tablas 1 y 2).

Se detectó infección por el VPH en 60 de las 112 muestras (53.5\%). El genotipo más frecuente fue el $\mathrm{VPH}-11$, en 51 muestras (45.5\%), seguido por el VPH52 en 27 (24.1\%), el VPH-16 en 9 (8.0\%) y el VPH-45 en $3(2.6 \%)$. Se detectó coinfección por más de un genotipo en 31 muestras (27.6\%), siendo la más
Tabla 1. Características clínicas e histopatológicas de 112 pacientes del noreste de México con cáncer de laringe clasificados de acuerdo con la identificación de VPH en el tejido laríngeo

\begin{tabular}{|c|c|c|c|c|}
\hline & $\begin{array}{c}\text { Total } \\
(n=112)\end{array}$ & $\begin{array}{l}\text { Con VPH } \\
(n=60)\end{array}$ & $\begin{array}{c}\text { Sin VPH } \\
(n=52)\end{array}$ & $\mathrm{p}$ \\
\hline Edad (años)* & $65.3 \pm 10.1$ & $65.5 \pm 8.9$ & $64.9 \pm 11.4$ & 0.756 \\
\hline $\begin{array}{l}\text { Sexo } \\
\text { Masculino } \\
\text { Femenino }\end{array}$ & $\begin{array}{c}107(95.5 \%) \\
5(4.5 \%)\end{array}$ & $\begin{array}{c}58(54.2 \%) \\
2(40 \%)\end{array}$ & $\begin{array}{c}49(45.8 \%) \\
3(60 \%)\end{array}$ & 0.432 \\
\hline $\begin{array}{l}\text { Muestra } \\
\text { Biopsia } \\
\text { Laringectomía }\end{array}$ & $\begin{array}{l}72(64.3 \%) \\
40(35.7 \%)\end{array}$ & $\begin{array}{l}33(45.8 \%) \\
27(67.5 \%)\end{array}$ & $\begin{array}{l}39(54.2 \%) \\
13(32.5 \%)\end{array}$ & 0.022 \\
\hline $\begin{array}{l}\text { Localización } \\
\text { Glótica } \\
\text { Subglótica } \\
\text { Supraglótica } \\
\text { Transglótica }\end{array}$ & $\begin{array}{c}65(58.0 \%) \\
4(3.6 \%) \\
17(15.2 \%) \\
26(23.2 \%)\end{array}$ & $\begin{array}{c}32(49.2 \%) \\
3(75.0 \%) \\
11(64.7 \%) \\
14(53.8 \%)\end{array}$ & $\begin{array}{c}33(50.8 \%) \\
1(25.0 \%) \\
6(35.3 \%) \\
12(46.2 \%)\end{array}$ & 0.556 \\
\hline $\begin{array}{l}\text { Diagnóstico } \\
\text { histopatológico } \\
\text { CEBDI } \\
\text { CEMDQ } \\
\text { CEMDNQ } \\
\text { CEPD }\end{array}$ & $\begin{array}{c}11(9.8 \%) \\
96(85.7 \%) \\
3(2.7 \%) \\
2(1.8 \%)\end{array}$ & $\begin{array}{c}5(45.5 \%) \\
53(55.2 \%) \\
2(66.7 \%) \\
0(0 \%)\end{array}$ & $\begin{array}{c}6(54.5 \%) \\
43(44.8 \%) \\
1(33.3 \%) \\
2(100 \%)\end{array}$ & 0.406 \\
\hline $\begin{array}{l}\text { Tabaquismo } \\
\text { Sí } \\
\text { No }\end{array}$ & $\begin{array}{c}108(96.4 \%) \\
4(3.6 \%)\end{array}$ & $\begin{array}{c}57(52.8 \%) \\
3(75 \%)\end{array}$ & $\begin{array}{c}51(47.2 \%) \\
1(25 \%)\end{array}$ & 0.365 \\
\hline $\begin{array}{l}\text { Alcoholismo } \\
\text { Sí } \\
\text { No }\end{array}$ & $\begin{array}{c}9(8.0 \%) \\
103(92.0 \%)\end{array}$ & $\begin{array}{c}7(77.8 \%) \\
53(51.5 \%)\end{array}$ & $\begin{array}{c}2(22.2 \%) \\
50(48.5 \%)\end{array}$ & 0.120 \\
\hline
\end{tabular}

*Al momento de la toma de la biopsia o la laringectomía.

Los valores se presentan como media \pm desviación estándar o como frecuencia absoluta (porcentaje).

CEBDI: carcinoma epidermoide bien diferenciado invasor; CEMDNQ: carcinoma epidermoide moderadamente diferenciado no queratinizante; CEMDQ: carcinoma epidermoide moderadamente diferenciado queratinizante; CEPD: carcinoma epidermoide poco diferenciado.

frecuente la coinfección por VPH-11 y VPH-52 (Tabla 2). No hubo diferencia significativa entre los pacientes con y sin infección por VPH en cuanto a distribución por edad, sexo, localización y diagnóstico histopatológico del tumor, ni en cuanto al antecedente de tabaquismo o alcoholismo $(p>0.05)$ (Tabla 1).

\section{Discusión}

El cáncer de laringe representa el $21.7 \%$ de las neoplasias malignas de las vías aerodigestivas superiores, y tiene como factores de riesgo principales el tabaquismo y el alcoholismo; la información en la literatura internacional es escasa con respecto a la infección por el VPH como posible factor de riesgo ${ }^{1-4}$. La presencia del VPH en el cáncer de laringe ha sido reportada en el 0 al $80 \%$ de los $\operatorname{casos}^{9-17}$. En México existen publicados tres estudios relacionados con el 
Tabla 2. Características clínicas e histopatológicas, y genotipos de VPH, en 60 pacientes con cáncer de laringe del noreste de México

\begin{tabular}{|c|c|c|c|c|c|c|c|c|}
\hline Paciente & Edad & Sexo & Muestra & Localización & $\begin{array}{l}\text { Diagnóstico } \\
\text { histopatológico }\end{array}$ & Tabaquismo & Alcoholismo & $\begin{array}{c}\text { Genotipo (s) } \\
\text { de VPH }\end{array}$ \\
\hline 1 & 54 & $\mathrm{~F}$ & Biopsia & Glótica & CEMDQ & Sí & No & 11 \\
\hline 2 & 66 & M & Biopsia & Supraglótica & CEBDI & Sí & Sí & 11 \\
\hline 3 & 66 & M & Biopsia & Glótica & CEMDQ & Sí & No & 11 \\
\hline 4 & 54 & M & Biopsia & Glótica & CEMDQ & Sí & No & 11,16 \\
\hline 5 & 64 & M & Laringectomía & Transglótica & CEMDQ & Sí & No & 11 \\
\hline 6 & 64 & M & Biopsia & Glótica & CEMDQ & Sí & No & $11,16,40,82$ \\
\hline 7 & 70 & M & Laringectomía & Glótica & CEMDQ & Sí & No & 11 \\
\hline 8 & 52 & M & Biopsia & Glótica & CEMDQ & Sí & No & 11 \\
\hline 9 & 67 & M & Biopsia & Supraglótica & CEMDQ & Sí & No & 11 \\
\hline 10 & 67 & M & Biopsia & Glótica & CEMDQ & Sí & Sí & 11 \\
\hline 11 & 58 & M & Laringectomía & Subglótica & CEMDQ & Sí & No & 11 \\
\hline 12 & 71 & M & Laringectomía & Transglótica & CEMDQ & Sí & No & 11 \\
\hline 13 & 59 & M & Biopsia & Glótica & CEMDNQ & Sí & No & 16 \\
\hline 14 & 49 & M & Laringectomía & Transglótica & CEBDI & Sí & No & 11 \\
\hline 15 & 66 & M & Biopsia & Glótica & CEMDQ & Sí & No & 11 \\
\hline 16 & 65 & M & Laringectomía & Glótica & CEMDQ & Sí & Sí & 11 \\
\hline 17 & 67 & M & Biopsia & Supraglótica & CEMDQ & Sí & No & 11 \\
\hline 18 & 76 & M & Biopsia & Supraglótica & CEMDQ & Sí & No & 11 \\
\hline 19 & 80 & M & Biopsia & Glótica & CEMDQ & No & No & 11 \\
\hline 20 & 61 & M & Laringectomía & Subglótica & CEMDQ & Sí & Sí & 52 \\
\hline 21 & 53 & M & Laringectomía & Transglótica & CEMDQ & Sí & No & 16 \\
\hline 22 & 61 & M & Biopsia & Supraglótica & CEMDQ & Sí & No & 52 \\
\hline 23 & 63 & M & Biopsia & Glótica & CEMDQ & Sí & No & 16 \\
\hline 24 & 68 & M & Biopsia & Supraglótica & CEMDQ & Sí & No & 11,16 \\
\hline 25 & 79 & M & Biopsia & Supraglótica & CEMDQ & Sí & No & 11 \\
\hline 26 & 81 & M & Biopsia & Glótica & CEMDQ & Sí & No & 11,52 \\
\hline 27 & 67 & M & Biopsia & Glótica & CEMDQ & Sí & No & 11,16 \\
\hline 28 & 71 & M & Laringectomía & Transglótica & CEMDQ & Sí & No & $6,11,52$ \\
\hline 29 & 80 & M & Biopsia & Supraglótica & CEMDQ & Sí & No & 6,11 \\
\hline 30 & 63 & M & Laringectomía & Transglótica & CEMDQ & Sí & No & 11,52 \\
\hline 31 & 68 & M & Laringectomía & Glótica & CEMDQ & No & Sí & $11,45,52$ \\
\hline 32 & 83 & M & Biopsia & Supraglótica & CEMDQ & Sí & No & $6,11,52$ \\
\hline 33 & 66 & M & Biopsia & Glótica & CEMDQ & Sí & No & 52 \\
\hline 34 & 60 & M & Laringectomía & Transglótica & CEMDQ & Sí & No & 11,52 \\
\hline 35 & 67 & M & Biopsia & Glótica & CEBDI & Sí & No & 45 \\
\hline 36 & 69 & M & Biopsia & Glótica & CEMDQ & Sí & No & $6,11,52$ \\
\hline
\end{tabular}


Tabla 2. Características clínicas e histopatológicas, y genotipos de VPH, en 60 pacientes con cáncer de laringe del noreste de México (Continuación)

\begin{tabular}{|c|c|c|c|c|c|c|c|c|}
\hline Paciente & Edad & Sexo & Muestra & Localización & $\begin{array}{l}\text { Diagnóstico } \\
\text { histopatológico }\end{array}$ & Tabaquismo & Alcoholismo & $\begin{array}{c}\text { Genotipo (s) } \\
\text { de VPH }\end{array}$ \\
\hline 37 & 60 & M & Laringectomía & Glótica & CEMDQ & Sí & No & 11,45 \\
\hline 38 & 72 & $\mathrm{~F}$ & Biopsia & Glótica & CEBDI & Sí & No & 11,52 \\
\hline 39 & 72 & M & Laringectomía & Glótica & CEMDQ & Sí & No & 11,52 \\
\hline 40 & 51 & M & Laringectomía & Transglótica & CEMDQ & Sí & No & 52 \\
\hline 41 & 61 & M & Biopsia & Glótica & CEMDQ & Sí & No & 11,52 \\
\hline 42 & 78 & M & Biopsia & Glótica & CEMDQ & Sí & Sí & 11,16 \\
\hline 43 & 61 & M & Laringectomía & Transglótica & CEMDQ & Sí & No & $6,11,52$ \\
\hline 44 & 56 & M & Laringectomía & Subglótica & CEMDQ & Sí & No & 11,52 \\
\hline 45 & 62 & M & Biopsia & Glótica & CEMDQ & Sí & No & 11,52 \\
\hline 46 & 79 & M & Biopsia & Glótica & CEMDQ & Sí & No & 11,52 \\
\hline 47 & 84 & M & Laringectomía & Glótica & CEMDQ & Sí & No & $6,11,52$ \\
\hline 48 & 55 & M & Biopsia & Glótica & CEMDQ & Sí & No & $6,11,52$ \\
\hline 49 & 65 & M & Laringectomía & Transglótica & CEMDQ & Sí & Sí & $11,16,52$ \\
\hline 50 & 58 & M & Laringectomía & Transglótica & CEMDQ & Sí & No & 11,52 \\
\hline 51 & 72 & M & Laringectomía & Transglótica & CEMDQ & No & No & 11,52 \\
\hline 52 & 74 & M & Laringectomía & Transglótica & CEMDQ & Sí & No & 11,52 \\
\hline 53 & 67 & M & Laringectomía & Glótica & CEMDQ & Sí & No & 52 \\
\hline 54 & 72 & M & Laringectomía & Supraglótica & CEMDQ & Sí & No & 11 \\
\hline 55 & 64 & M & Laringectomía & Glótica & CEMDQ & Sí & No & 11 \\
\hline 56 & 44 & M & Laringectomía & Transglótica & CEMDQ & Sí & No & 11 \\
\hline 57 & 62 & M & Biopsia & Supraglótica & CEMDQ & Sí & No & 11,52 \\
\hline 58 & 70 & M & Biopsia & Glótica & CEMDNQ & Sí & No & 11,52 \\
\hline 59 & 49 & M & Biopsia & Glótica & CEMDQ & Sí & No & 11,52 \\
\hline 60 & 72 & M & Laringectomía & Glótica & CEMDQ & Sí & No & 11,52 \\
\hline
\end{tabular}

CEBDI: carcinoma epidermoide bien diferenciado invasor; CEMDNQ: carcinoma epidermoide moderadamente diferenciado no queratinizante; CEMDQ: carcinoma epidermoide moderadamente diferenciado queratinizante; M: masculino; F: femenino.

tema: en el primero de ellos, 16 de 32 muestras de pacientes con cáncer de laringe fueron positivas para VPH (50\%), en el segundo se demostró VPH en 4 de 16 muestras de pacientes con cáncer de laringe (25\%), y en el tercero solo en 2 de 45 muestras de pacientes con cáncer de laringe pudo detectarse el VPH $(4.4 \%)^{9,18,19}$.En el presente estudio se evaluaron la prevalencia y los genotipos del VPH en muestras de tejido laríngeo de pacientes con cáncer de laringe que recibieron atención en una unidad médica de tercer nivel de atención del noreste de México.

La edad de presentación de los pacientes fue alrededor de 65 años, lo cual concuerda con lo descrito en la literatura internacional, ya que el cáncer de laringe ocurre con más frecuencia en la sexta década de la vida ${ }^{1,2}$. No se encontraron casos de pacientes en edad pediátrica con cáncer de laringe. Existen hasta la fecha cerca de 80 pacientes con cáncer de laringe en edad pediátrica reportados desde el año 1868, algunos de ellos relacionados con infección por el $\mathrm{VPH}^{20-24}$.En este estudio predominaron los pacientes del sexo masculino, lo cual concuerda con lo descrito previamente, ya que el cáncer de laringe afecta en especial a los hombres ${ }^{1,2}$. Joos, et al. ${ }^{22}$, en el año 2009, reportaron una predominancia del sexo masculino hasta del $80 \%$; sin embargo, esta relación 
es diferente en la población juvenil, en quienes se ha reportado solo el $60 \%$ de predominio del sexo masculino. En años recientes se ha observado un cambio en el patrón de comportamiento del cáncer de laringe, incluyendo un aumento de su frecuencia en personas jóvenes, mujeres y personas no consumidoras de tabaco ni alcohol ${ }^{22,25}$.

El $96.4 \%$ de los pacientes con cáncer de laringe del presente estudio tenían el antecedente de tabaquismo, lo cual es mayor que lo reportado en estudios previos. En el Reino Unido tienen el antecedente de tabaquismo hasta el $79 \%$ de los pacientes con cáncer de laringe ${ }^{26}$. Las personas con tabaquismo tienen un riesgo relativo hasta 8.3 veces mayor de desarrollar cáncer de laringe comparado con personas que nunca han fumado 27 .

La frecuencia de alcoholismo en la muestra del presente estudio fue del $8 \%$. El alcoholismo aumenta hasta cuatro veces el riesgo de desarrollar cáncer de laringe cuando el consumo de alcohol es $\geq 25$ onzas por mes, en comparación con personas no alcohóli$\mathrm{cas}^{28}$. Además, se ha identificado una relación positiva entre el consumo de alcohol y la localización de la neoplasia en la laringe de predominio supraglótica ${ }^{29}$. En las muestras laríngeas con infección por VPH del presente estudio, la localización más frecuente fue la glótica, seguida de la transglótica y la supraglótica; un orden de localización similar al reportado en una revisión sistemática reciente ${ }^{13}$.La escasa prevalencia de VPH en los tumores supraglóticos es explicable por el hecho de que estos tienen una asociación más importante con el consumo de alcohol ${ }^{29}$.

En el presente estudio se detectó ADN del VPH en el $53 \%$ de las muestras analizadas. Hobbs, et al. ${ }^{8}$ evaluaron la relación entre el VPH y el cáncer de cabeza y cuello, demostrando una fuerte asociación con cánceres localizados en las amígdalas (Razón de Momios [RM]: 15.1; Intervalo de Confianza [IC] 95\%: 6.8-33.7), un riesgo intermedio para el resto de la orofaringe (RM: 4.3; IC 95\%: 2.1-8.9) y un riesgo muy débil para la cavidad oral (RM: 2.0; IC 95\%: 1.2-3.4) y la laringe (RM: 2.0; IC 95\%: 1.0-4.2). La prevalencia de infección por VPH en el cáncer de laringe es variable, oscilando entre el 0 y el $80 \% \%^{9-17}$. En México solo hay tres estudios que reportan la prevalencia de la infección por VPH en el cáncer de laringe: uno realizado en una muestra de 16 pacientes con una prevalencia del $25 \%$, otro en 32 pacientes con una prevalencia del $50 \%$, y otro que evaluó 45 pacientes con una prevalencia del $4.4 \% 9,18,19$. Por lo tanto, la prevalencia de infección por VPH en el cáncer de laringe detectada en la presente serie es la más alta reportada en México. Debe tenerse en cuenta que en el presente estudio se contó con un mayor número de muestras que en los estudios previos realizados en México ${ }^{9,18,19}$. La amplia variabilidad en la prevalencia del VPH entre los estudios podría deberse a sesgos en la selección de muestras, diferencias en las técnicas utilizadas para la detección del VPH, diferentes sitios anatómicos de toma de muestras, pobre calidad de las muestras o diferencias genéticas, étnicas, geográficas y culturales de los individuos ${ }^{12,13}$.

El genotipo de VPH más frecuente en este estudio fue el 11 , en el $45 \%$ de las muestras, seguido por el 52 en el $24 \%$ y el 16 en el $8.0 \%$. Otros genotipos detectados fueron el 6 , el 45 , el 82 y el 40 . Los genotipos 6,11 y 40 son de bajo riesgo oncogénico, mientras que los genotipos 16, 45, 52 y 82 son de alto riesgo oncogénico ${ }^{5}$. Es notable la baja prevalencia de VPH-16 detectada en la presente serie, puesto que en otros estudios ha sido el genotipo que más se ha asociado a la patogénesis del carcinoma laríngeo $0^{6-9}$. Villagómez-Ortiz, et al. ${ }^{19}$, en el año 2016, reportaron el genotipo VPH-11 en 2 de 45 muestras estudiadas. Este genotipo muestra un comportamiento más agresivo en pacientes con papilomatosis laríngea recurrente, quienes requieren un mayor número de resecciones quirúrgicas al año ${ }^{30}$. Hay casos que describen la transformación de papilomatosis laríngea recurrente en carcinoma epidermoide en presencia de infección por genotipos de bajo riesgo, como el 6 y el $11^{31}$.

En este estudio se encontró coinfección por más de un genotipo en 31 muestras (27.6\%), y la coinfección más frecuente fue por VPH-11 y VPH-52, genotipos de bajo y alto riesgo oncogénico, respectivamente. La coinfección por más de un genotipo fue reportada en dos de las 16 muestras examinadas en uno de los estudios previos realizados en México, y fue por genotipos de bajo y alto riesgo ${ }^{18}$. Esto sugiere que, en algunos casos de cáncer de laringe, el VPH podría estar involucrado independientemente de su riesgo oncogénico, o bien que ambos grupos de genotipos virales podrían actuar de manera singérgica ${ }^{18}$. En el presente estudio se identificó un caso de coinfección por los genotipos 11, 16, 40 y 82; en la literatura internacional solo existen los reportes de dos casos de cáncer laríngeo relacionados con el VPH-82, uno de ellos en coinfección con VPH-73 32,33 .

Dentro de las posibles implicaciones clínicas de la infección por VPH como agente causal de cáncer de laringe, se esperaría que los genotipos presentes en este semejen a los hallados en lesiones de cérvix, 
toda vez que la contaminación orogenital es la ruta de transmisión propuesta como más frecuente. Por lo tanto, el papel en la prevención de cánceres de cabeza y cuello, incluido el cáncer de laringe, de las vacunas contra el VPH actualmente disponibles en el mercado es aún desconocido ${ }^{12}$. Así mismo, la infección por VPH en el cáncer de laringe abre la posibilidad a nuevas terapias dirigidas a células infectadas por VPH como blanco ${ }^{12}$. Por otro lado, resulta de interés conocer el pronóstico de estos pacientes, toda vez que hay reportes de una mayor respuesta terapéutica y sobrevida en pacientes con cáncer de orofaringe asociado a infección por VPH ${ }^{34-36}$.

\section{Conclusiones}

Los resultados del presente estudio muestran una prevalencia de la infección por VPH en muestras de tejido laríngeo de pacientes con cáncer de laringe del $53.5 \%$, con coinfección por más de un genotipo en el $27.6 \%$ de las muestras. El genotipo más frecuente fue el VPH-11, tipo de bajo riesgo, seguido por el VPH-52, genotipo de alto riesgo oncogénico, pero se detectó infección por genotipos de alto riesgo en el $34.8 \%$ de las muestras. Un resultado positivo para ADN del VPH amplificado por Reacción en Cadena de la Polimerasa (PCR) solo demuestra su presencia y no necesariamente implica su papel en la carcinogénesis. Se requiere la realización de estudios epidemiológicos a mayor escala, no sólo con muestras mayores, sino también que incluyan la evaluación simultánea de hallazgos histopatológicos, inmunohistoquímicos, de hibridación in situ y de amplificación de ADN por $\mathrm{PCR}$, a fin de conocer la verdadera prevalencia de infección por VPH en la mucosa laríngea y el cáncer de laringe. Esto permitiría, además, contar con una evidencia más sólida de su verdadero potencial oncogénico en la laringe, así como de su posible interacción con factores de riesgo bien establecidos, como el consumo de alcohol y tabaco. También queda por establecer el pronóstico de los pacientes con cáncer de laringe asociado a infección por VPH, así como el impacto a largo plazo sobre el desarrollo de esta enfermedad de las vacunas actualmente disponibles.

\section{Responsabilidades éticas}

Protección de personas y animales. Los autores declaran que para esta investigación no se han realizado experimentos en seres humanos ni en animales.

Confidencialidad de los datos. Los autores declaran que han seguido los protocolos de su centro de trabajo sobre la publicación de datos de pacientes.

Derecho a la privacidad y consentimiento informado. Los autores declaran que en este artículo no aparecen datos de pacientes.

\section{Conflicto de intereses}

Los autores declaran no tener ningún conflicto de intereses.

\section{Financiamiento}

El presente estudio fue financiado a través de un fondo aprobado por el Programa de Apoyo a la Investigación Científica y Tecnológica (PAICYT 2015, con No. de registro SA156-15).

\section{Agradecimientos}

Un agradecimiento especial a la QCB Silvia Margarita García Herrera, de Medicina Diagnóstica de Monterrey, México, por su asistencia en el proceso de histotecnología en la obtención de muestras por sacabocados (punch). El Dr. Gerardo C. Palacios fue apoyado por una Beca de Excelencia en Investigación de la Fundación IMSS, A.C.

\section{Bibliografía}

1. Siegel RL, Miller KD, Jemal A. Cancer statistics, 2016. CA Cancer J Clin. 2016;66:7-30.

2. Flint PW. Epidemiology. En: Armstrong WB, Vokes DE, Maisel RH, editors. Cummings Otolaryngology - Head and neck surgery. Philadelphia: Mosby Elsevier; 2010. p. 107.

3. Durán de Alba LM, Roa Castro FM. Risk factors for developing laryngeal cancer in adult population at the Hospital Español in Mexico city. Acta Otorrinolaringol Esp. 2008;59:367-70.

4. Gorgoulis V, Zacharatos P, Kotsinas A, Kyroudi A, Rassidakis AN, Ikonomopuulos JA, et al. Human papillomavirus (HPV) is possibly involved in laryngeal but not in lung carcinogenesis. Hum Pathol. 1999;30:274-83.

5. Muñoz N, Bosch FX, de Sanjosé S, Herrero R, Castellsaqué X, Shah KV, et al. Epidemiologic classification of human papillomavirus types associated with cervical cancer. N Engl J Med. 2003;348:518-27.

6. Morshed K, Stenzel A, Szymański M, Rózyńska K, Siwiec H, Gołabek W, et al. Detection of human papillomavirus type 16 and 18 in laryngeal cancer using PCR. Otolaryngol Pol. 2001;55:29-33.

7. Liu B, Lu Z, Wang P, Basang Z, Rao X. Prevalence of high-risk human papillomavirus types (HPV-16, HPV-18) and their physical status in primary laryngeal squamous cell carcinoma. Neoplasma. 2010;57:594-600.

8. Hobbs CG, Sterne JA, Bailey M, Heyderman RS, Birchall MA, Thomas SJ. Human papillomavirus and head and neck cancer: a systematic review and meta-analysis. Clin Otolaryngol. 2006;31:259-66.

9. Gallegos-Hernández J, Paredes-Hernández E, Flores-Díaz R, Minauro-Muñoz G, Apresa-García T, Hernández-Hernández DM. Human papillomavirus: association with head and neck cancer. Cir Cir. 2007;75:151-5.

10. Badaracco G, Rizzo C, Mafera B, Pichi B, Giannarelli D, Rahimi SS, et al. Molecular analyses and prognostic relevance of HPV in head and neck tumours. Oncol Rep. 2007;17:931-9. 
11. Gillison M, Koch W, Capone RB, Spafford M, Westra WH, Wu L, et al. Evidence for a causal association between human papillomavirus and a subset of head and neck cancers. J Natl Cancer Inst. 2000;92:709-12.

12. Torrente MC, Rodrigo JP, Haigentz M Jr, Dikkers FG, Rinaldo A, Takes RP, et al. Human papillomavirus infections in laryngeal cancer. Head Neck. 2011;33:581-6.

13. Li X, Gao L, Li H, Gao J, Yang Y, Zhou F, et al. Human papillomavirus infection and laryngeal cancer risk: a systematic review and meta-analysis. J Infect Dis. 2013;207:479-88.

14. Morshed K. Association between human papillomavirus infection and laryngeal squamous cell carcinoma. J Med Virol. 2010;82:1017-23.

15. Baumann JL, Cohen S, Evjen AN, Law JH, Vadivelu S, Attia A, et al. Human papillomavirus in early laryngeal carcinoma. Laryngoscope. 2009;119:1531-7.

16. Gungor A, Cincik H, Baloglu H, Cekin E, Dogru S, Dursun E. Human papilloma virus prevalence in laryngeal squamous cell carcinoma. J Laryngol Otol. 2007;121:772-4

17. Kreimer AR, Clifford GM, Boyle P, Franceschi S. Human papillomavirus types in head and neck squamous cell carcinomas worldwide: a systematic review. Cancer Epidemiol Biomarkers Prev. 2005;14:467-75.

18. Manjarrez ME, Ocadiz R, Valle L, Pacheco C, Marroquín A, De la Torre C et al. Detection of human papillomavirus and relevant tumor suppressors and oncoproteins in laryngeal tumors. Clin Cancer Res. 2006;23:6947-51.

19. Villagómez-Ortiz VJ, Paz-Delgadillo DE, Marino-Martínez I, Ceseñas-Falcón LA, Sandoval-de la Fuente A, Reyes-Escobedo A. Prevalencia de infección por virus del papiloma humano en carcinoma espinocelular de cavidad oral, orofaringe y laringe. Cir Cir. 2016; 84:363-8.

20. Balakrishnan R, Chowdhury Q, Hussain M, Hassan M, Haque N, Sharmeen $\mathrm{F}$, et al. Early glottic squamous cell carcinoma in a 16 year old case report, review of literature and pediatric head and neck radiotherapy guidelines. Case Rep Oncol. 2015;8:363-8.

21. McDermott A, Raj P, Glaholm J, Pearman K, Macnamara M. De novo laryngeal carcinoma in childhood. J Laryngol Otol. 2000;114:293-5.

22. Joos B, Joos N, Bumpous J, Burns C, French CA, Farghaly H. Laryngeal squamous cell carcinoma in a 13 year old child associated with human papilloma viruses 16 and 18: a case report and review of the literature. Head Neck Pathol. 2009;3:37-41.

23. Gindhart TD, Johnston WH, Chism SE, Dedo HH. Carcinoma of the larynx in childhood. Cancer. 1980;46:1683-7.
24. Rastogi M, Srivastava M, Bhatt MLB, Srivastava K, Bhatia N. Laryngeal carcinoma in a 13-year-old child. Oral Oncol Extra. 2005;41:207-10.

25. León X, Rinaldo A, Saffiotti U, Ferlito A. Laryngeal cancer in non-smoking and non-drinking patients. Acta Otolaryngol. 2004;124:664-9.

26. Parkin DM, Boyd L, Walker LC. The fraction of cancer attributable to lifestyle and environmental factors in the UK in 2010. Br J Cancer. 2011;105:S77-81.

27. Wyss A, Hashibe M, Chuang SC, Lee YC, Zhang ZF, Yu GP, et al. Cigarette, cigar, and pipe smoking and the risk of head and neck cancers: pooled analysis in the International Head and Neck Cancer Epidemiology Consortium. Am J Epidemiol. 2013;178:679-90.

28. Altieri A, Garavello W, Bosseti C, Gallus S, La Vecchia C. Alcohol consumption and risk of laryngeal cancer. Oral Oncol. 2005;41:956-65.

29. La Vecchia C, Zhang ZF, Altieri A. Alcohol and laryngeal cancer: an update. Eur J Cancer Prev. 2008;17:116-24

30. Gerein V, Rastorguev E, Gerein J, Draf W, Schirren J. Incidence, age at onset, and potential reasons of malignant transformation in recurrent respiratory papilomatosis patients: 20 years of experience. Otolaryngol Head Neck Surg. 2005;132:392-4.

31. Jeong WJ, Park SW, Shin M, Lee YJ, Jeon YK, Jung YH, et al. Presence of HPV type 6 in dysplasia and carcinoma arising from recurrent respiratory papillomatosis. Head Neck. 2009;31:1095-101.

32. Si-Mohamed A, Badoual C, Hans S, Péré H, Tartour E, Brasnu D. An unusual human papillomavirus type 82 detection in laryngeal squamous cell carcinoma: case report and review of literature. J Exp Clin Virol. 2012:54:190-3.

33. Pannone G, Sanguedolce F, Santoro A, Fierro P, Panetti M, Fierro D, et al. Detection of novel human papillomavirus type 82 in laryngeal cancer: case report. Auris Nasus Larynx. 2010;37:648-50.

34. Ang KK, Harris J, Wheeler R, Weber R, Rosenthal DI, Nguyen-Tân PF, et al. Human papillomavirus and survival of patients with oropharyngeal cancer. N Engl J Med. 2010;363:24-35.

35. Fakhry C, Westra WH, Li S, Cmelak A, Ridge JA, Pinto H, et al. Improved survival of patients with human papillomavirus-positive head and neck squamous cell carcinoma in a prospective clinical trial. J Natl Cancer Inst. 2008;100:261-9.

36. Ragin CC, Taioli E. Survival of squamous cell carcinoma of the head and neck in relation to human papillomavirus infection: review and meta-analysis. Int J Cancer. 2007;121:1813-20. 